\title{
Air Medical Interventions at Comatose Pediatric Patients in Eastern Romania - Particularities of Airway Management and Cardio-Pulmonary Resuscitation
}

\author{
ANGEL LIVIU TRIFAN ${ }^{1,2}$, LILIANA DRAGOMIR ${ }^{1,3}$, EVA-MARIA ELKAN ${ }^{3,4 *}$, VIOLETA SAPIRA ${ }^{1,3}$, \\ MIHAELA LUNGU ${ }^{1,3}$, MONICA ZLATI ${ }^{5}$, ANA-MARIA PAPUC ${ }^{6}$, LAURA FLORESCU ${ }^{7}$, \\ MAGDA MIULESCU ${ }^{3,4}$, DIANA CARMEN CIMPOESU ${ }^{8,9}$, PAUL LUCIAN NEDELEA ${ }^{2,8}$ \\ ${ }^{1}$ Emergency County Hospital "Sfantul Apostol Andrei", Emergency Department, 177 Brailei Str., 800578, Galati, \\ Romania \\ ${ }^{2}$ Grigore T. Popa University of Medicine and Pharmacy, 16 Universitatii Str., 700115, Iasi, Romania \\ ${ }^{3}$ Dunarea de Jos University of Medicine and Pharmacy, 47 Domneasca Str., 800008, Galati, Romania \\ ${ }^{4}$ Sfantul Ioan Emergency Hospital, 2 Gheorghe Asachi Str., 800487, Galati, Romania \\ ${ }^{5}$ Stefan cel Mare University, 13 Universitatii Str., 720229, Suceava, Romania \\ ${ }^{6}$ Dunarea de Jos University of Medicine and Pharmacy, AMG, 47 Domneasca Str., 800008, Galati, Romania \\ ${ }^{7}$ Grigore T.Popa University of Medicine and Pharmacy, Department Mother and Child, 16 Universitatii Str., 700115, \\ Iasi, Romania \\ ${ }^{8}$ Sfantul Spiridon Emergency Clinical Hospital, 1 Independentei Blvd.,700111, Iasi, Romania \\ ${ }^{9}$ Grigore T.Popa University of Medicine and Pharmacy, II-nd Surgical Department, 16 Universitatii Str., 700115, Iasi, \\ Romania
}

Pediatric comas are particular situations of terrestrial or aerial medical intervention, requiring knowledge of specific protocols and prioritization and hierarchy of emergency interventions. The reactivity of the comatose child is modified according to multiple biological, physiological parameters and generating pathologies. The study aims to analyze the specific elements of aerial medical interventions with helicopter, HEMS (Helicopter Emergency Medical Service) at comatose child that influences the emergency path, but especially the medium and long term prognosis of these cases. The transfer of comatose children at Galati aeromedical base, both primary and secondary interventions, were studied. The study was a prospective randomized study involving pediatric comas transferred over a 4-year course (2014-2017) according to the criteria in force. A total of 24 children between the ages of 0-18 years were transferred, with primary and secondary interventions. In the study lot, the correlations between Glasgow scores and associated pathology, epidemiological characteristics, therapeutic elements, complications and case evolution were analyzed. A profile of the patient requiring emergency intervention for the comatose state was created, making it possible to predict the services they will need and to design the specialized interventions that will follow the transfer of these patients. Although still intensely disputed due to cost considerations, the air transfer of the comatose child facilitates a more prompt response of medical systems to manage this type of emergency and presents management particularities in pre-hospital. Based on this type of results, a strategy takes shape by which the Romanian emergency system aligns with the continuous improvement of life-saving interventions for children.

Keywords:Aerial Medical Transfer (HEMS), children, comas, associated pathologies

For any patient who has suffered an injury and has his/her general state influenced, it is important to manage the time required both for intervention at the destabilizing event site and for bringing it to a near hospital as soon as possible. In the 1970s a golden hour concept emerged in which fundamental maneuvers could be made for the subsequent good evolution of decompensated cases. As the state of coma is known to have multiple causes that may be vascular, traumatic, metabolic, intoxication, hereditary decompensated metabolic diseases, immunological. Rapid management of a coma case minimizes its impact on the child's body by influencing it in the long run. The condition of coma is often not defined very clearly, nor does it suffer from a very fixed frame, especially as for staff coming into contact with a comatose child the technical and emotional challenge is immense. The transport of a comatose child requires special preparations both before and after, but also after receiving the patient by the unit. The device that maintains the vital support must be checked, like the aircraft, the delicate maneuvers in the air requiring strong team cohesion. Not to be neglected is the psychic state of the staff during the mission, rest periods being essential, therefore the entire team's knowledge of the incidents and accidents that occur is strictly necessary.

\section{Study of the specialized literature}

Coma [1] involves a state of inhibition of varying degrees of nervous activity. The patient's consciousness is totally or partially lost, and motility is also suppressed. Reactions to external stimulation are nonspecific and vegetative functions are maintained [2]. 
In Germany, interventions for pediatric emergencies are 2-9\% of all missions. The groups most affected by children requiring emergency intervention are, according to the German authors, 0-5 year olds as well as the 14-16 year olds, and the pediatric intubation is still high, $20 \%$ of the patients requiring emergency specialized intervention. Presentation with GCS $<9$ points was $16.3 \%$ at pediatric patients [3].

Not to be neglected is the number of people killed by fatal accidents in the world, 1.3 million / year [4].

\section{Intervention time}

Traumatology is known to have golden hour - patients can die in the first hour after the accident. It is precisely the decrease in these times possible due to assisted air transport in severely traumatized patients. Helicopter-assisted aerial medical services have been applied to civilian patients since the 1947s, benefiting from much faster and more trained crews than those on ambulances. There are also disadvantages of this type of transport: these services are much more expensive, the medical space for manoeuvre is very small, but also the risks given by the weather that makes helicopters collapse, endangering and crew`s and the patient'slives. That is why before the air transport there are still discussions between the specialists who make the decision for this type of transfer, and in the literature there is still controversy in some cases [5]. Air transport helps provide equal medical services irrespective of the patient's health status or social or economic background before the impact of the destabilizing event on its physical condition. These services will be continually improved by every country in the world [6].

In the case of accidents in general, the average time from the accident site to the hospital is 69.4 minutes with a standard deviation of $28.3 \mathrm{~min}$. These times are very variable in the case of motor vehicle accidents with the patient inside the vehicle and / or if he/she has claimed intubation. [1] In order to evaluate the power of intervention of a system, the term first intervention is used which applies to the one who appears first at the intervention site, such as authorities, family members, crew who intervene, etc. and how effective they can be, and times of intervention depends on this effectiveness that significantly influence the total time of intervention [7]. It is also essential to educate the population for timely intervention in a major emergency until the specialized crews come.

In the 1990s, only paramedical crews were chosen, but a doctor being in the helicopter lead to a better airway emergency management, more prompt patient analgesia, and even invasive helicopter procedures [8].

Helicopter alert can be split and refined in several times as proposed by Kruger so it is analyzed 1) the moment when the first emergency call comes 2) a type called the helicopter pre-dealer 3) the takeover of the helicopter by the crew 4) bringing the helicopter to take-off place 5) the effective take-off 5) reaching the hospital. In some areas missions have a seasonal summer pattern of $41 \%$, unlike winter where air transport is required in $67 \%$ of cases. The most frequent weekday flights were Wednesday and Sunday[9].

\section{Cardiopulmonary resuscitation and management of coma problems}

Cardiopulmonary resuscitation aims to re-establish vital functions. Goldberg has shown that advanced cardiopulmonary resuscitation may be considered to be complete if, for an hour, cerebral or cardiac functions did not respond after a cardiopulmonary arrest. However, at patients in whom spontaneous circulation has returned, the cerebral flow suffers a significant reduction for 18 hours from the time of its onset demonstrated by White et al [10].

Intubation is a very delicate moment for the emergency specialist, neurologist anesthetist, neurosurgeon. This decision is sometimes very difficult especially when preparing patients for brain operations knowing that the brain has a different behavior after applying protocols and the therapeutic induction of some. Protocols on advanced vital function support as well as traumatology protocols show that there are four post-trauma situations when intubation is required.

There is the notion of Schutzintubation used in German space, as it is sometimes intubation to a Glasgow even greater than 9 in some circumstances. Pre-hospital intubation adherents say that the patient is out of the agitation that can be installed after trauma, agitation that may occur in more complex mental disorders just after trauma at some patients. At the same time, these patients may develop more complications than non-intubated such as stasis pneumonia. Another disadvantage of intubation is hypotension, but also hypertonia that may occur at the time of induction to prepare for intubation. Intubation has the role of providing a better oxygenation of the organs. At the same time, intubated patients will receive more catechol amines as treatment than those who do not benefit from this maneuver. Sepsis is also higher at these patients [11].

The management of the volumes of liquids administered to the patient in the pre-hospital requires caution these volumes influencing the coagulation systems when they exceed $1500 \mathrm{~mL}$ administered. The amount of liquid increases as the blood pressure at the moment of take-up is lower such a threshold is at the blood pressure of $60 \mathrm{~mm}$ $\mathrm{Hg}$ when the volume of infusions administered is greater. Mortality increases proportionate to the hight of the volley correction intake [12]. Oligoalgezia is the term that defines the inappropriate and / or insufficient treatment for the acute-type pain, which is often found at the critical patient. A study of traumatic destabilized patients showed that $43 \%$ of patients had oligoalgezia [13]. 
Hipo / and / or Hyperthermia management

Patients who suffer from hypothermia require a careful evaluation because the temperature at which they are found prevails as well as the associated medical conditions. Before the patient is warmed up, the cardiopulmonary resuscitation is the one that needs to be taken into account first [14].

\section{Managing the hypoxic phenomena}

It is important to manage breathing, which can be assisted by special devices such as AirQLA, and the physician can visualize the airways through fiber optic as shown by Jagannathan et al. Thus, assisting ventilation on the mask that sometimes leads to hypoxia installation is replaced by this type of assisted ventilation, improving airway management thus becoming controlled and assisted [15].

\section{Management of Severe Poisoning}

Carbamazepine can cause coma by blocking sodium channels and acetylcholine synapses with the involvement of adenosine A1 receptors. In addition to this, cardiac arrhythmia, epileptic crying and respiratory failure may occur. Thus, in these situations, barbiturates for a therapeutic coma are also used to protect the brain from the destruction of carbamate-coma [16].

\section{Managing rare diseases causing coma}

Often pediatricians do not know or omit to look for rare coma-inducing diseases. On the surface are often the complications which are treated, the associated respiratory or cardiac failure, hypoxia, sepsis, bleeding. An example is the mixedematous coma that can surprise any pediatrician, although it appears rare and rare but can also occur in an infectious context. However, it must be considered because there are still many families who neglect the treatment for thyroid disease at children. The presentation may be misleading, consisting of signs such as low body temperature, but also alteration of cardiac and renal functions [17].

\section{Evaluation}

Different scores at patients experiencing consciousness help determine subsequent conduct. There is trauma score and the score of the vital signs. Of the two scores the trauma score gives a better insight into the risk of death. If this score is either equal to 12 or less than 12 the significance for a possible death is very high [18].

There is also a score called Therapeutic Intervention Scoring System (TISS). It can be applied more than one verification score on a patient. However, the Glasgow Score (GCS) remains the base, with Revised Trauma Score, NACA and Intervention Score (TISS) being the most commonly used trauma score [19]. A scale was designed for children and consists of four items of four points each. It encodes 4 items of ocular reactivity, motor reactivity, presence of cerebral torso reflexes, respiratory status. It is very difficult to say whether this pediatric scale is more accurate to assess the evolution of patients after the destabiliatory event than the Glasgow scale.

After the cardiopulmonary arrest, the EEG is one of the most accurate prognostic tests on the subsequent progression of cases that have benefited from support measures of vital functions. The stimulations to achieve an interpretive EEG response are the pressure at the navel bed (62\%) as well as the stern pressure (46\%) and for the chlidren are used the hearing impaired potentials (86\%), the nerve bed pressure (57\%) and $29 \%$ have used tracheal stimulation [20]. Assessing the impact of hepatic steatosis at obese patients can be done quickly ultrasonographically so hepatic function can also be appreciated from this prism[21].

There is a new method of investigating head trauma, facile, non-traumatic, called proximal infrared spectroscopy. It's a small device that can be manually operated and detects intracreberal bleeding. The wavelengths with which it operates are 600-1,000 nm, and this device is folding on air transport as it has already happened in Netherlands in a study [22].

There are a number of proteins secreted by neurons and glial claws in response to inflammation that can be measured in the blood, and whose values can be predictive for assessing the patient who suffered a severe cerebral trauma with coma. Osteopontin is secreted by macrophages and microglia when the brain suffers a severe lesion [23]. The assessment also includes an assessment of the context in which the injuries occurred, thus also defining a new type of rescue action for patients dedicated to extreme sports such as the passing of narrow canyons, sports practiced in very dangerous and turbulent waters [24]. Related to winter sports, the percentage of severely affected traumatized patients is higher among children than adults [25].

\section{Evolution and recovery}

In the case of trauma, any extra bleeding leads to a worse prognosis [12]. The term of vegetative state was introduced as a term by Jennett and Plum. It refers to apalic syndrome found in 0.5-2 / 100.000 cases at European patients in postresuscitation status. The efforts of rehabilitation of apalic patients and the adequacy of home services for them after they were discharged puts the medical systems in difficulty [26]. Despite the very good management of apalic patients, the mortality of patients with residual apalic syndrome still widely varies between $1.2 \%$ and $15.2 \%$ every year. There are still very large polemics about the active and /or passive euthanasia of these patients. Passive 
euthanasia would consist in withdrawing nutrition and hydration from these types of patients, a decision that is virtually impossible to take because forensic euthanasia is actually creating willingly the conditions for a person to die sooner [27].

Electroencephalogram is integrated into the comatose patient's monitoring tools that are hospitalized by anticipating the impact of cerebral disturbance events. The EEG monitors both patient recovery and the new pharmaco-EEG method. Somatosensory potentials evoked also measures the impact of the comatose patient's brain disruption, in this analysis the $\mathrm{P} 300$ wave being essential also with prognostic value. The gold standard of surveillance for these patients still remains the cerebral CT and the NMR that will be individualized chosen from case to case, but also according to the existing protocols for each particular condition in conformity with the guides in force. A followup protocol is a first evaluation after 3 weeks after leaving the coma with a 6-month repetition over a 3-year interval from the event [26].

The risk of brain death is directly influenced by intracerebral pressure, which in turn alters the infusion pressure. At children, intracranial pressure measurement is made less often than at the adult. Increased intracrebral pressure produces ischemia and irreversible brain damage, installing through this mechanism the brain death. It is possible to calculate risk classes that will influence this intracrebral pressure and therefore brain death so if there is a unilateral fixed mydriasis, the risk of cerebral death will increase 4 times [28].

The evolution of neonates is also influenced by how the mother takes care of them intrauterine so they can present coma because of the use of toxins by the mother, even if the urinary toxicological test is negative, it can be taken into consideration the coma given by the neonatal intrauterine exposure and then the management of these coma becomes extremely delicate [29].

Recovery of patients with neurological sequelae and major dysfunctions in everyday life respects several principles. In 1964 the Helsinki Declaration was made, which shows that the doctor has the duty to put in human service all the means to save the patient. The goal is to maximize the comfort, prevent and treat existing and potential complications, and at the same time to ensure a recovery as good as possible and to optimize the capacities of the organism to function at the highest level. German Coma Remission Scale GCG allows the evaluation of recovery after a coma in the most effective way. The environment in which these patients are recovered must be structured to adapt to the new postcomatose status [27]. Another problem not to be neglected at comatose patients is obesity, if present, these patients are much more difficult to manage. This can occur in metabolic X syndrome that includes central obesity and insulin resistance. Both type 1 diabetes and type 2 diabetes are more and more common at the child complicating both clinical pictures of different diseases and pediatric coma [30].

Diabetes having a ketoacidosis complication can lead to a life threatening vasogenic cerebral edema at the child. This type of impairment occurs at younger patients, newly diagnosed and correlated with a low socio-economic level [31]. A reason for these metabolic skews is also food that is richer in calories and salt, but cheaper for consumers, who think they are economizing, especially when a single fast-food meal can contain $2000 \mathrm{kcal}$ [32] and exposure to phthalates at obese children increases the metabolic drift of these obese children [33].

\section{$\underline{\text { Renal retention }}$}

This can also be due to acute renal failure and, on the other hand, the kidney is affected at $1 / 2$ of the patients who have experienced a coma. There is a link between kidney malfunction and inflammatory mechanisms of the brain, a mechanism that explains these phenomena by affecting renal clearance in serious pathological processes [34].

\section{Experimental part}

Material and methods

24 children with coma carried by helicopter were surveyed between 2014-2017, at the Galaţi Aeromedical Base. Coma is a medical emergency that needs to be treated with the utmost care. Medical protocols have been applied according to the medical guides present on the territory of Romania and according to the legal operation provisions in the authorized medical air transports. The study is observational mixed prospective randomized. We have evaluated the patients transported from Galati and the neighbouring settlements either to Galati or from Galati to Bucharest to a higher echelon. We want to highlight the intervals of intervention but also the correlation between pathologies most commonly encountered at our work point. At the same time, it was also wanted to highlight the optimal reaction times, the flight schedule and the flight routes were chosen under the Bucharest air traffic control and it was taken into account the weather conditions to offer the possibility of timely intervention and no accidents and incidents according to the legislation in force on the Romanian territory.

The inclusion criteria in the analyzed group were:

Child under 18 years old

A patient in coma when picked up by the helicopter crew

Patient transferred by medical helicopter

Base of operation Galati

Exclusion criteria:

Patient aged over 18 
A patient who is not comatose

Patient transferred by terrestrial means

A comatose patient ready for transfer but deceased before the transfer

We have evaluated the vital functions.

It were applied partition classes according to the age, gender, origin according to the aeromedical point, major pathologies, comorbidities, reaction times. Patients were evaluated using the Glasgow Scale at the time of take-over, parameters of vital functions were also taken, respiratory rate, tension, $\mathrm{SaO}_{2}$. Oxygen saturation has been an extremely important parameter.

\section{Results and discussions}

At the level of Aeromedical Base Galati, between 2014 and 2017 a number of 14 children in coma were transported. The rapidity of the intervention was relatively high, four speed reaction rates were identified from the time of the helicopter alert until the take-off.

Thus, $21.43 \%$ of the cases were between $4-5$ minutes, $21.49 \%$ of the cases, $6-7$ minutes $35.71 \%$ of patients, and the $7-9$ minute response in $21.43 \%$ of patients. Primary interventions were $42.85 \%$ and secondary interventions were $57.14 \%$.

The sex of the patients illustrates that $64.29 \%$ of the cases were males and $35.71 \%$ of the cases were females as seen in Figure 1.

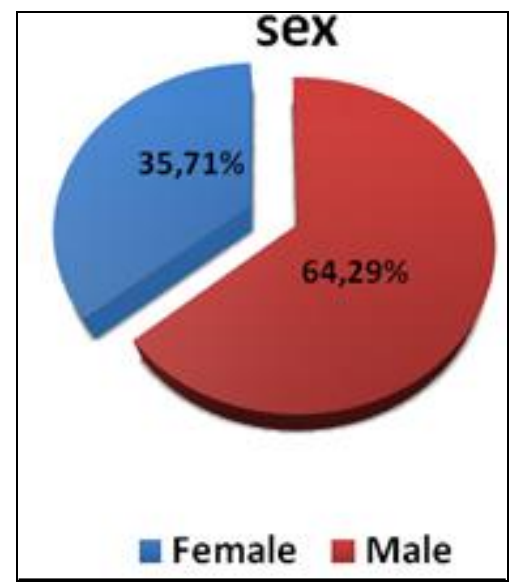

Fig. 1. Sex of pediatric air transported patients in coma

Glasgow Coma Score we have divided into 4 classes, so GCS=3-6 points were 78.57\% of cases, Glasgow score 7-9 were $7.14 \%$ of cases, $10-12$ were $0.00 \%$, and $13-15$ were $14.29 \%$ of the cases as shown in Figure 2. As is known the decrease of the Glasgow score by 2 points is a severity index, and the Glasgow scores indicated were those at takeover. A child may come with a Glasgow of 10 points and may follow the medical interventions to increase in points, but he will under certain conditions still benefit from air transfer as the generating factor of gravity is still persisting. This explains some higher scores in our series.

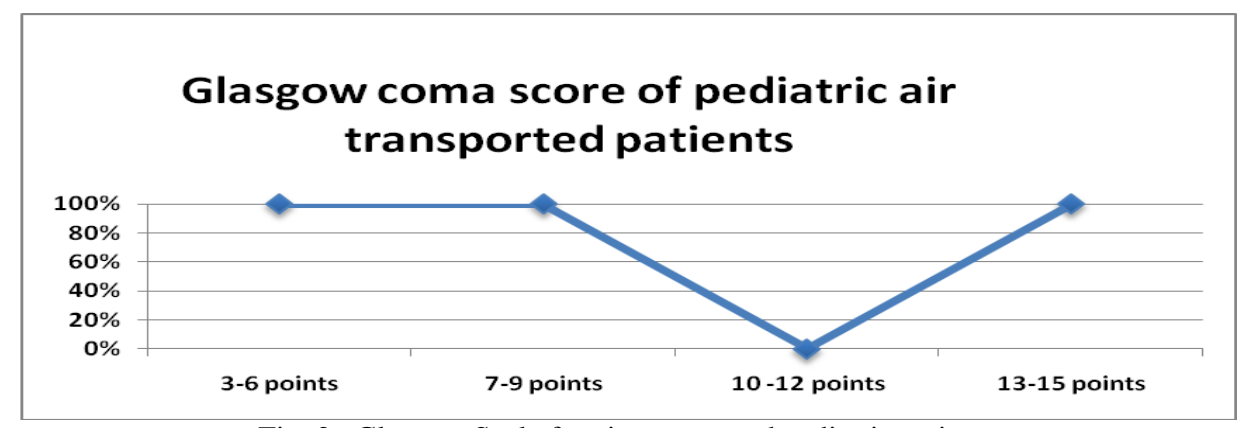

Fig. 2. Glasgow Scale for air transported pediatric patients

Another factor of case severity analysis is the others parameters of vital functions, so the respiratory rate was 12-16 breaths per minute at $64.29 \%, 16-18$ breaths per minute $14.29 \%, 18-20$ breaths per minute were $7.14 \%$ of patients and 20-25 breaths per minute or more had $14.29 \%$ of patients as shown in Figure 3. 


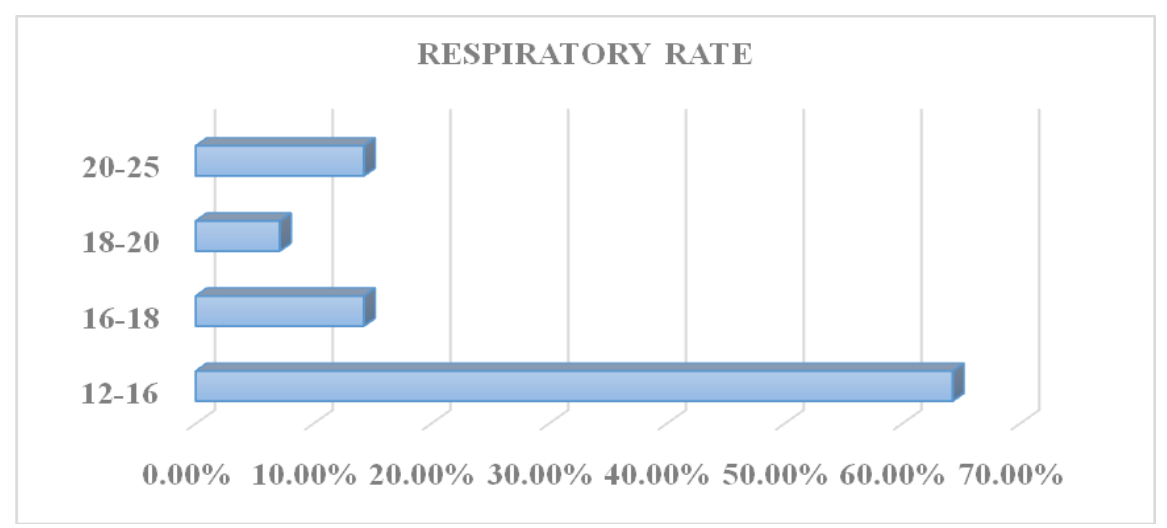

Fig. 3. Respiratory rate at air transported pediatric patients in coma

The heart rate and pulse were analyzed in the following groups:75-90 beats per minute were $14.29 \%$ of patients, 90-110 beats per minute were $21.43 \%, 110-120$ beats per minute in case of $28.57 \%$ of patients and heart rates between $120-160$ beats per minute in case of $28.57 \%$ of pediatric patients. Figure 4 show the distribution of heart rates.

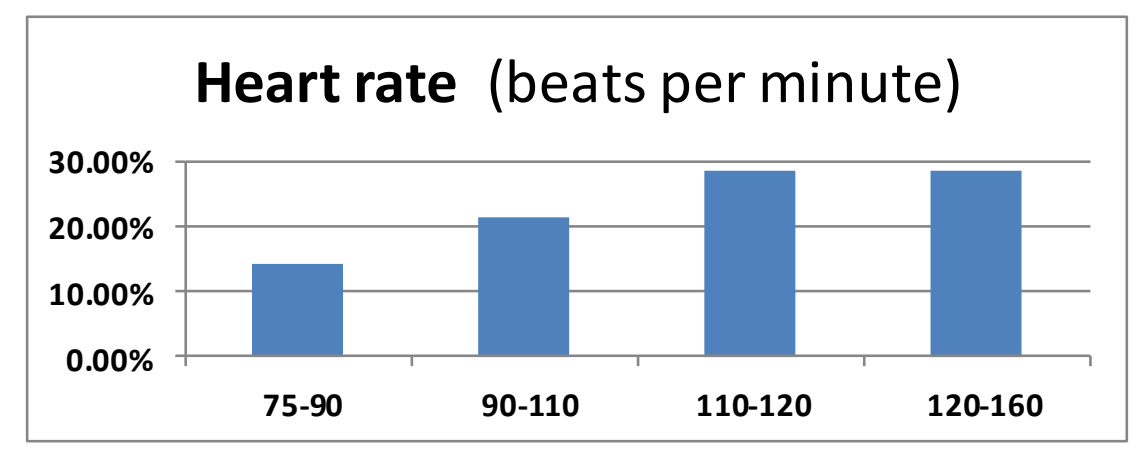

Fig. 4. The distribution of heart rate and pulse at air transported comatose children

Blood pressure distribution was as follows: hypotensive are $28.57 \%$, normal $57.14 \%$ and hypertensive $14.57 \%$, how can we see in Figure 5.

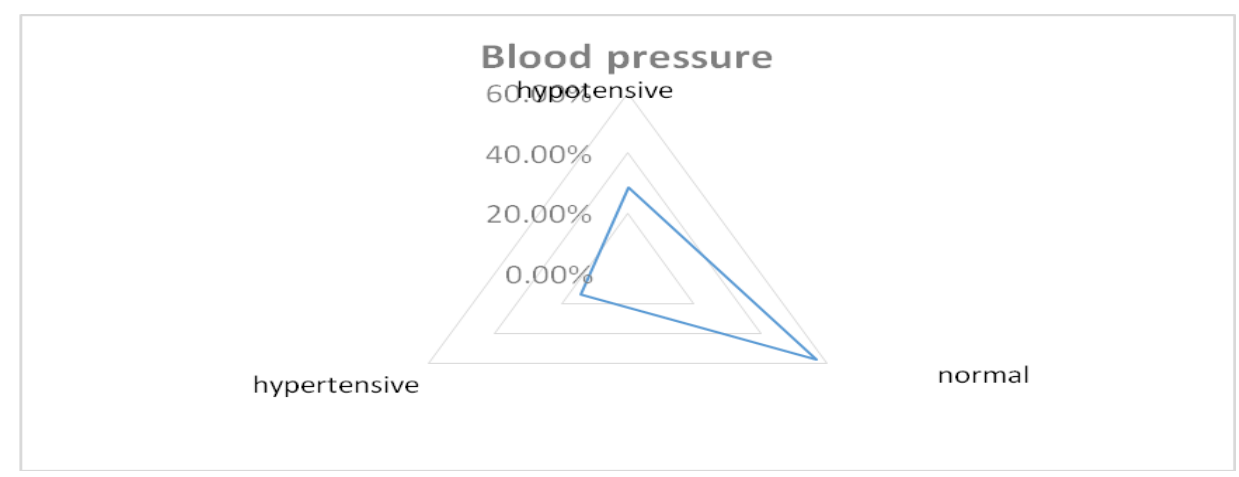

Fig.5. Blood pressure distribution at air transported pediatric patients

The oxygen saturation was analyzed and were obtained the following values: $\mathrm{SpO}_{2}$ 75-80\% was found at $14.29 \%$, $80-85 \%$ was $00.00 \%, 90-95 \%$ was at $78.57 \%$ of patients, as illustrated in figure 6 .

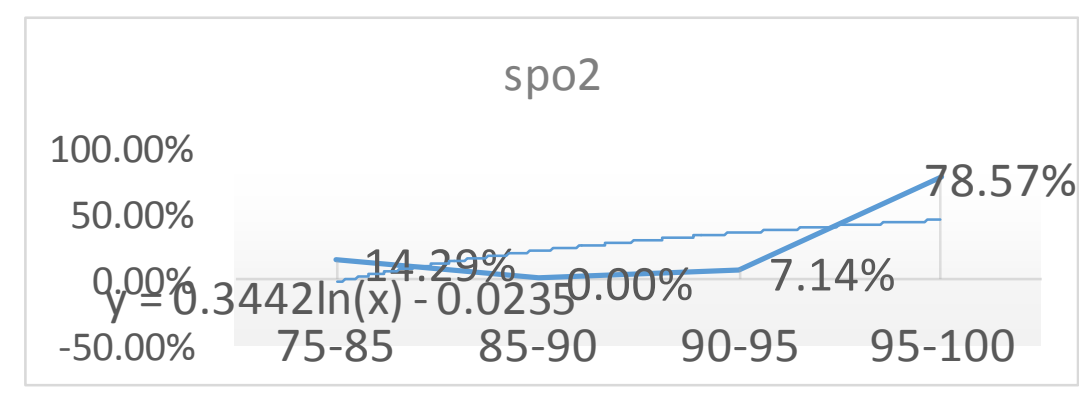

Fig. 6. The distribution of pediatric patients in coma transferred by helicopter 
In the case of blood glucose, $85.71 \%$ of patients were normal at the time of transport, so they had no diabetes, but $14.29 \%$ had glucose metabolism difficulties, since the percentage of young diabetic patients continuing to rise. This fact is illustrated in figure 7 .

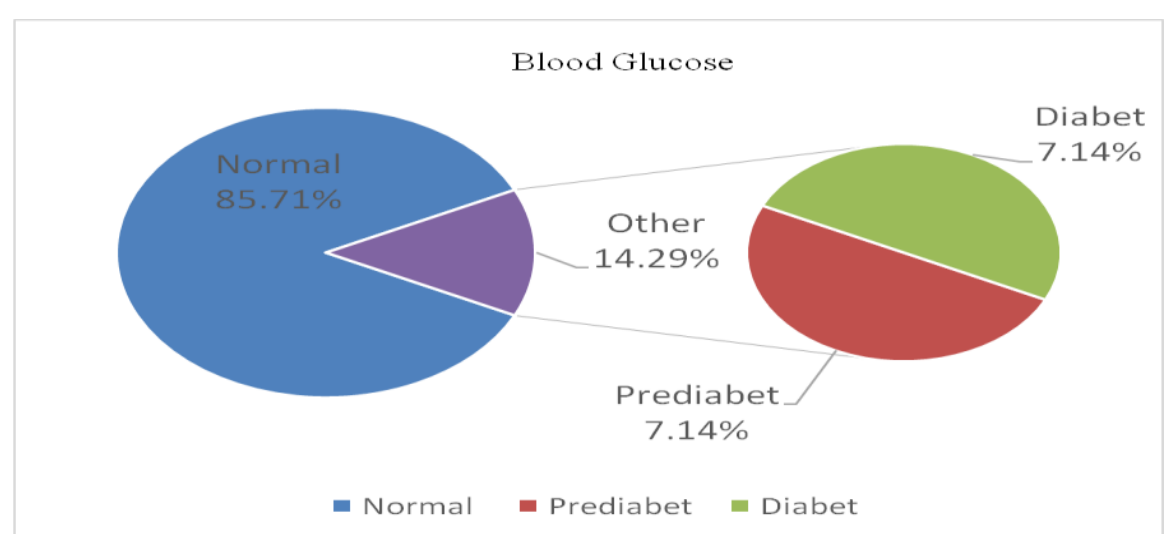

Fig. 7. Distribution of blood glucose value at air transported pediatric patients in coma

Patients who used the Guedel pipe were $14.29 \%$ because a percentage already required intubation, or there were mixed intubated situations after all, that started with the Guedel pipe and then the patient was intubated after all. The use of the Guedel pipe is shown in figure 8.

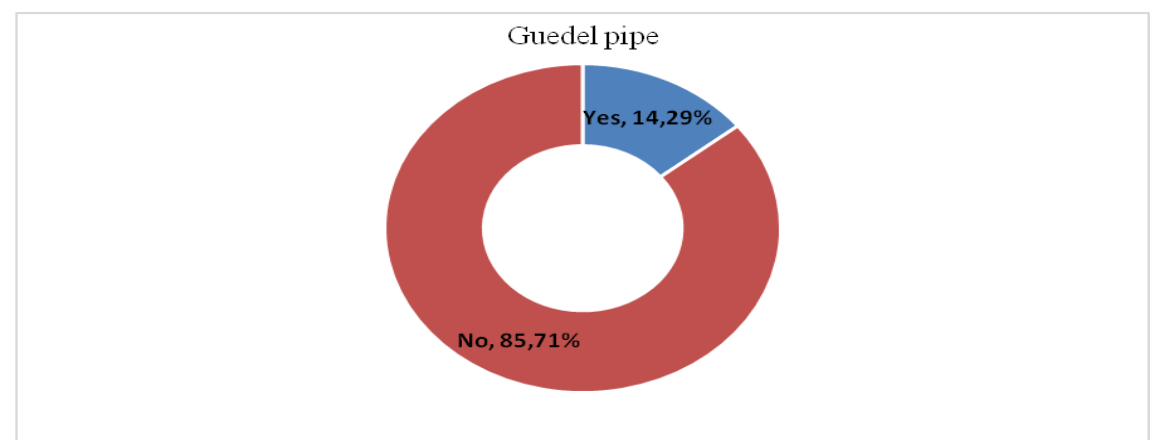

Fig. 8. The use of the Guedel pipe at air transferred pediatric comatose patients

Endotracheal intubation is an important and necessary moment in sustaining the critical patient. Successful intubation involves safety, solid knowledge and technical skills. Non-intubated patients were $35.71 \%$, intubated without induction were $21.43 \%$ of patients, and patients with rapid sequence intubation were $42.86 \%$ of patients. Induction is often very necessary when conditions impose intubation, and for intubation in comfort and not to produce patient injuries is preferable the endotracheal intubation with induction as shown in figure 9.

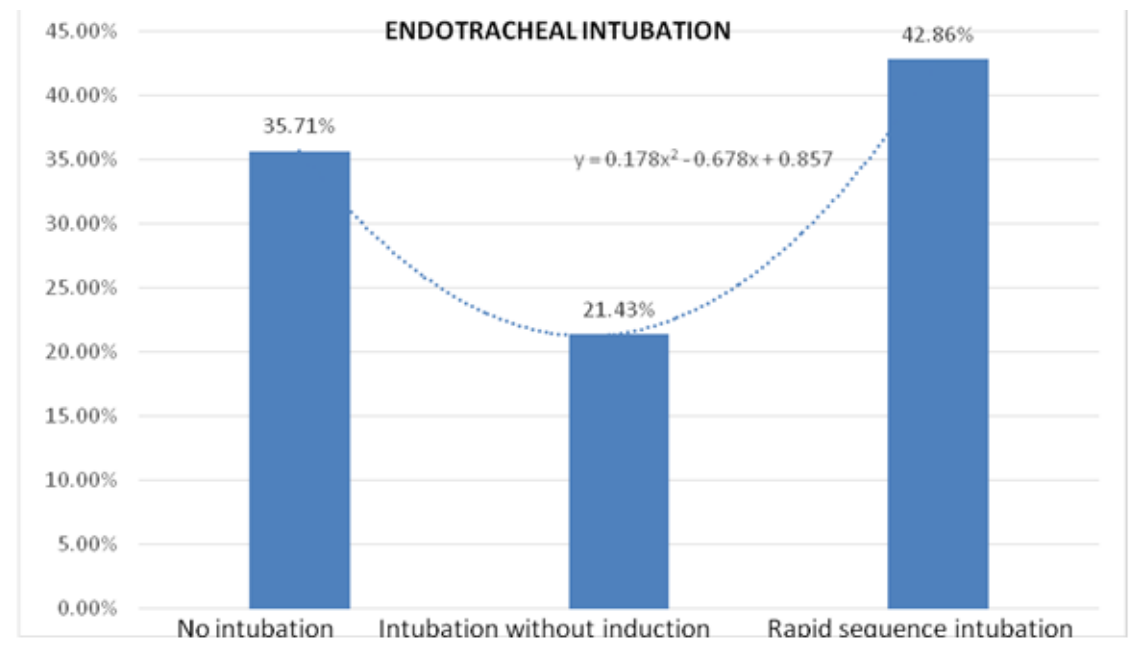

Fig.9. Endotracheal intubation with and without induction at air transferred pediatric comatose patients

The haemostasis maneuvers were necessary at a few patients, in $7.14 \%$, and $92.86 \%$ do not necessitate haemostasis. The need for a haemostasis, especially on a large blood vessel greatly complicates the clinical picture and the entire emergency response.

Advanced cardiopulmonary resuscitation was required in $14.29 \%$ of cases, the children being found in cardiorespiratory stop or cardiac arrest during the intervention. The reasons for requesting the helicopter either at the 
domicile or other location, or at the hospitals for air transfer were analyzed. Three major medical conditions were the criteria for initiating aeromedical intervention: resuscitated cardiorespiratory stop (21.43\%), coma of unspecified aetiology $(28.57 \%)$ and diagnosis of intoxication (14.29\%).

A statistical pattern has been developed to evaluate witch case is more frequent, a pattern of cases witch will generate a more focused and specialized response from the HEMS-helicopter emergency medical services. In Table 1 the cases were represented according to the need for intubation, the necessity of mechanical ventilation, if the intubation was with or without induction, if the aspiration was necessary, the Glasgow coma score type.

The resulting model is a male patient - decided after having a $64 \%$ prevalence, more likely the age of 1-2 years (42\%), transported with secondary mission type - $51 \%$ of cases, and after a first presentation in an Emergency Department of a first hospital from where it refers to a superior echelon. The patient profile is that of a very seriously ill patient with a GCS of 3-6 points, with a pulse of 110-120 beats per minute, but with medical efforts, the oxygen saturation was maintained at good parameters, at 90-92\%, without pathological history known of hyperglycemia with a probability of $85.71 \%$, who can usually be intoxicated in $35.71 \%$ of cases, is taken by helicopter, intubated and mechanical ventilated in $42.86 \%$, and from those ventilated the need for aspiration is $71.43 \%$.

Tabel 1

THE PATTERN OF CASES WITH THE HIGHEST PROBABILITY OF OCCURRING FOR HEMS MEDICAL INTERVENTIONS AT THE AEROMEDICAL POINT GALATI.

\begin{tabular}{|c|c|c|c|c|c|c|c|}
\hline sex & age & departure & arrival & $\begin{array}{c}\text { type of } \\
\text { intervention }\end{array}$ & time to takeoff & $\begin{array}{c}\text { Glasgow Coma } \\
\text { Score }\end{array}$ & $\begin{array}{c}\text { respiratory } \\
\text { rate }\end{array}$ \\
\hline $\begin{array}{c}\text { male } \\
=64.29 \%\end{array}$ & $\begin{array}{c}1-2 y e a r s \\
=42.86 \%\end{array}$ & $\begin{array}{c}\text { Galaţi } \\
=35.71 \%\end{array}$ & $\begin{array}{c}\text { București } \\
=50 \%\end{array}$ & $\begin{array}{c}\text { Secondary } \\
=57.14 \%\end{array}$ & $\begin{array}{c}6-7 \text { minutes } \\
=35.71 \%\end{array}$ & $\begin{array}{c}3-6 \text { points } \\
=78.57 \%\end{array}$ & $\begin{array}{c}12-16 / \text { minute } \\
=64.29 \%\end{array}$ \\
\hline $\begin{array}{c}\text { pulse/heart } \\
\text { rate }\end{array}$ & $\begin{array}{c}\text { blood } \\
\text { pressure }\end{array}$ & $\mathbf{S a ~ O 2}$ & $\begin{array}{c}\text { blood } \\
\text { glucose }\end{array}$ & $\begin{array}{c}\text { mechanical } \\
\text { ventilation }\end{array}$ & $\begin{array}{c}\text { intubation with } \\
\text { induction }\end{array}$ & Intoxication & \\
\hline $\begin{array}{c}110-120 \mathrm{bpm} \\
=28.577 \%\end{array}$ & $\begin{array}{c}\text { Normal } \\
57.14 \%\end{array}$ & $\begin{array}{c}90-95 \% \\
=78.57 \%\end{array}$ & $\begin{array}{c}\text { Normal } \\
=85.71 \%\end{array}$ & $\begin{array}{c}\text { No } \\
=42.86 \%\end{array}$ & $\begin{array}{c}\text { No } \\
=42.86 \%\end{array}$ & Yes $=35.71 \%$ & \\
\hline
\end{tabular}

Helicopter response times can always be improved by constant and good communication with the pediatric service that sends, but also with the ambulance that brings the child to the helicopter, thus, by knowing the case in advance, the speed reaction increases and the response is faster and more appropriate to the pathology in question. On the other hand, they cannot be artificially decreased because the flight preparing involves checks and stages beyond which it cannot be overtaken. The Glasgow Coma Score analysis shows that a helicopter is predominantly required for the deep coma of Glasgow score of 3-6 points when each won minute is vital. But the gravity of a case is not only reflected by the Glasgow Scale.

The air transport differs greatly according to the region due to the differences regarding the endowment and the appreciation of emergency where we cannot speak yet about a complete unitary vision. There is European Aviation Safety Agency (EASA) which sets the flight policy in the European Union. Under such conditions, night flight missions can also be provided. However, the regulations for night flight in primary missions are not yet clear even in some German Länders. There is the possibility of a night-time navigation using special night glasses that are approved under some circumstances as well as using advanced systems such as night vision googles (NVG). It must be licensed both the night flight crew and the helicopter to have certain facilities, but an essential role is played by the weather conditions.

For example, for a two-pilots flight, the horizontal visibility must be at least 2500 meters and the clouds span at 1200 feet height. ( EU Directive 965 // 2012 SPA HEMS 120) [35]. With a very high probability of cardiopulmonary arrest at seriously ill patients, it is good for certain groups of people to have basic concepts of cardiopulmonary resuscitation (Basic Life Support) through authorized courses by authorized trainers in order to be trained for these situations [36,37]. Thus, we see the relatively high rate of mobilization in Goteborg community, where cardiopulmonary resuscitation by people who are not active in sanitary field has increased in recent years from $31 \%$ to $47 \%$ in 2004, this being the result of population's education programs and in institutions [38]. When intubation fails, it generates many frustrations and many accidents and incidents of intubation are due to the fact that physicians are sometimes too proud to call a colleague to support them, but generally the teams are pre-established in advance and such incidents happen less and less often. The statistical model developed is very sensitive to international protocols and statistics. The predominantly exposure of boys and also young boys is also linked to a gender-related vulnerability. Even though the patient has signs of gravity with a much lower Glasgow often up to 3-6 points, however, there is a very good reaction speed of UPU-SMURD services in Romania reflected by getting a good oxygen saturation through medical interventions because the goal is saving patient's life and his/her functions of the highest possible level, depending on the patient's previous problems. In Romania, there are many disputes between clinicians (neurologists, neurosurgeons and air and ground prehospital crew members) whether or not the patient is intubated, as neurosurgeons' argument is that after sedation / intubation is much more difficult to operate for the brain behaves differently at a lasting coma induction because the local infusion of the brain is changing [39-41]. However, we usually intubate at 7 Glasgow points, but in Germany they intubate even greater than 9 points in some circumstances. The statistical model elaborated shows that in Romania, however, the probability of the patient being accidentally 
intoxicated with various substances found at home still persists. In the rural environment, children can find different solutions for household such as entomoxane which is intended for the disinfestation of sheep and with high toxicity for the nervous system after ingestion by children and high risk of death, organophosphorus products. Intoxication with nitrite remains another public health problem.

Another way through which patients are poisoned is with antiepileptics, antidepressants or with trihexiphenydil, which is associated with these treatments. Because of the new lifestyle with occupations that keep parents very busy and grandparents often absent from the extended family life, children can often escape unsupervised and take the parents` and / or grandparents medicines, who develop depression just because they cannot manage a balanced life on multiple plans $[42,43]$.

Another way of presenting, which is not yet found in our statistical model but is already noted in some situations and is more and more common in the world, is that of extreme sports, in which groups of amateurs arrogate their performances (skateboards, bikes on dangerous surfaces and trampolines, parcour practiced by children in gangs). That is why some insurance houses have considered how to ensure those who want to practice such sports, and to compel them to be more responsible towards their own lives. We can talk about mountain sports like climbing or skiing of a certain type [44].

There have been intense discussions in recent years at us as well as in other countries if in some cases at children due to the existing pressure and the emotional impact of a coma child we made an excessive triage of the children to be transported by helicopter or where ground emergency services would be just as effective, the idea being that sometimes valuable resources are consumed which in other cases cannot beused when a life is in danger, and this subject is still alive and they are many polemics $[45,46]$. In this sense, it is beneficial for us to train pediatricians who are already in pediatric emergency departments in emergency medicine.

\section{Conclusions}

Child intoxication is a major reason for aerial medical interventions in the eastern region of Romania, the prevention being essential (parents need to be educated regarding the use of toxic substances in households).

The use of induction medication it is not always necessary, orotracheal intubation not being the only modality of airway management during transport.

Understanding the roles of the team members, the succession of the times of maneuver, the preparation for transfer of the comatose patient streamlines the services, increasing the efficiency, the promptness of the missions and the shortening of the time for the stabilization of the patient in the hospital after arrival as well as a better and more comfortable life for the patient and his / her family.

\section{References}

1.WYEN, H., LEFERING, R., MAEGELE, M., BROCKAMP, T., et col. DGU The golden hour of shock - how time is runningout: prehospital time intervals in Germany - a multivariate analysis of 15, 103 patients from the TraumaRegister. Emerg Med J 2013;30:1048-1055.

2. POPOVICIU, L., PASCU, I., Tratat de Neurologie C. Aseni volum IV Editura Medicala București 1979,Principii terapeutice în neurologie 253-581, Tratamentul bolnavilor comatoși p.390-395

3.HELM, M., BIEHN, G., LAMPL, L., BERNHARD, M., Pädiatrischer Notfallpatient im Luft rettungsdienst Einsatzrealität unter besonderer Berücksichtigung,,invasiver“" Maßnahmen Anaesthesist. 2010 Oct; 59(10):896-903.

4.GONIEWICZ, K., GONIEWICZ, M., PAWŁOWSKI, W., FIEDOR, P., Road accident rates: strategies and programmes for improving road traffic safety,Eur J Trauma Emerg Surg.2016 Aug; 42 (4): 433-438

5.MICHAELS, D., PHAM, H., PUCKETT. Y., Dissanaike S,Helicopter versus ground ambulance: review of national database for outcomes in survival in transferred trauma patients in the USATrauma Surg Acute Care Open. 2019; 4(1): e000211

6.RZONCA, P., SWIEZEWSKI, S.P., JALALI, R., GOTLIB. J., Helicopter Emergency Medical Service (HEMS) Response in Rural Areas in Poland: Int J Environ Res Public Health. 2019 Apr 30;16(9). pii: E1532. doi: 10.3390/ijerph16091532.

7.BOLZ, A., New approaches in first aid for cardiovascular patients. Biomed Tech (Berl). 2002 Oct;47(9-10):258-67.

8.ROBERTS, K., BLETHYN, K., FOREMAN, M., BLEETMAN, A., Influence of air ambulance doctors on on-scene times, clinical interventions, decision-making and' independent paramedic practice Emerg Med J. 2009 Feb;26(2):128-34. doi: 10.1136/emj.2008.059899.

9.DETHLEFF, D., WEINREICH, N., KOWALD, B., HORY, D., et col. Air Medical Evacuations From the German North Sea wind Farm Bard Offshore 1: Traumatic injuries, Acute diseases, and Rescue process Times ( 2011-2013) Air medical Journal 35 (2016) 216-226

10.SMITH, J.P., BODAI, B.I., Guidelines for discontinuing prehospital CPR in the emergency department--a review Ann Emerg Med. 1985 Nov;14(11):1093-8.

11.HUSSMANN, B., LEFERING, R., WAYDHAS, C., RUCHHOLTZ, S., et col. Prehospital intubation of the moderately injured patient: a cause of morbidity? A matched-pairs analysis of 1,200 patients from the DGU Trauma Registry Crit Care. 2011;15(5):R207.

12.HUSSMANN, B., LEFERING, R., WAYDHAS, C., TOUMA, A., et col. Does increased prehospital replacement volume lead to a poor clinical course and an increased mortality? A matched-pair analysis of 1896 patients of the Trauma Registry of the German Society for Trauma Surgery who were managed by an emergency doctor at the accident site Injury, Int. J. Care Injured 44 (2013) 611-617

13.ALBRECHT, E., TAFFE, P., YERSIN, B., SCHOETTKER, P., et col. Undertreatment of acute pain (oligoanalgesia) and medical practice variation in prehospital analgesia of adult trauma patients: a $10 \mathrm{yr}$ retrospective study .Br J Anaesth. 2013 Jan;110(1):96-106.

14.KJAERGAARD, B., RUDOLPH, S.F., LUCAS, A., HOLDGAARD, H.O., Treatment of the hypothermic patient. Ugeskr Laeger. 2008 Jun 2;170(23):2005-10.

15.ADS, A., AUERBACH, F., RYAN, K., EL-GANZOURIAIR, A.R.,Q laringeal airway for rescue and tracheal intubation Journal of clinical anteshezia 2016.02.004

16.AGULNIK, A., KELLY, D.P., BRUCCOLERI, R., YUSKAITIS, C., Conbination Clearanche therapy and Barbiturate coma for severe Carbamazepine Overdose Pediatrics volume 139nr 5 may 2017:e20161560

17.ROOT, J.M., VARGAS, M., GARIBALDI, L.R., SALADINO, R.A., Pediatric Patient With Altered Mental Status and Hypoxemia Case Report. Pediatric Emergency Care ; Vol. 00, Nr 00, Month 2016 
18.DEANE, S.A., GAUDRY, P.L., ROBERTS, R.F., JUUL, O., LITTLE, J.M., Trauma triage--a comparison of the trauma score and the vital signs score. Send to Aust N Z J Surg. 1986 Mar;56(3):191-7.

19.SAVITSKY, E., RODENBERG, H., Prediction of the intensity of patient care in prehospital helicopter transport: use of the revised trauma score. Aviat Space Environ Med. 1995 Jan;66(1):11-4

20.HIRSCH, J., LEE, J.W., CASH, S.S., WESTOVER, M.B., EEG Reactivity Evaluation Practices for Adult and Pediatric Hypoxic-Ischemic Coma Prognostication in North America, Journal of Clinical Neurophysiology Volume 35, Number 6, November 2018 p.510-514

21.PLEȘEA-CONDRATOVICI, C., PLEȘEA-CONDRATOVICI, A., NEAMȚU, C., BANU, M., Coupling computer-aided ultrasound methods with V-CAD reconstructioin to virtual characterization of hepatic steatosis The Annals of "Dunărea de Jos" University of Galați Fascicle V, Techonologies in Machine Building, ISSN 1221- 4566, 2012

22.JOOST PETERS, J., VAN WAGENINGEN, B., HOOGERWERF, N., TAN, E., et col. Near-Infrared Spectroscopy: A Promising Prehospital Tool for Management of Traumatic Brain Injury Vol. 32, No. 4

23.GAO, N., ZHANG-BROTZGE, X., WALI, B., SAYEED, I., et col. Plasma osteopontin may predict neuroinflammation and the severity of pediatric traumatic brain injury J Cereb Blood Flow Metab. 2019 Mar 13:271678X19836412.

24.SOTERAS, I., SUBIRATS, E., STRAPAZZON, G., Epidemiological and medical aspects of canyoning rescue operations Injury, INT. J. Care injuried 46( 2015) 585-589

25.McCOWAN, C.L., SWANSON, E.R., THOMAS, F., HARTSELL, S., TODD, L., et col. (2006) Scene Transport of Pediatric Patients Injured at Winter Resorts, Prehospital Emergency Care, 10:1, 35-40

26.WILD K,GERSTENBRAND F, DOLCE G, BINDER H et col., Guidelines for Quality Management of Apallic Syndrome / Vegetative State Eur J Trauma Emerg Surg. 2007 Jun;33(3):268-92.

27.Von WILD, K., Neuroethics with regard to treatment limiting and withdrawal of nutrition and hydration in long lasting irreversible full state Apallic Syndrome and Minimal Conscious State J Med Life. 2008 Nov 15; 1(4): 443-453.

28.KADA, A.Y., BOUYOUCEF, K.A., La mort encéphalique post traumatique: épidémiologie et facteurs de risque Pan Afr Med J. 2018; 31 : 29.

29.DYER, E.M., SALEHIAN, S., How to interpret urine toxicology tests . Arch Dis Child Educ Pract Ed 2019;0:1-5. doi:10.1136/archdischild2018-316139

30.ALIREZA, ANSARIMOGHADDAM, HOSSEIN, ALI., ADINEH, ZEREBAN IRAJ, IRANPOUR SOHRAB, HOSSEINZADEH ALI A. ANSARIMOGHADDAM,et al.,Prevalence of metabolic syndrome in Middle-East countries: Meta-analysis of cross-sectional studies, Diab Met Syndr: Clin Res Rev Diabetes Metab Syndr. 2018 Apr - Jun;12(2):195-201

31.OSTOJIC, S., VUKOVIC, R., MILENKOVIC, T., MITROVIC, K., et col.Alpha coma in an adolescent with diabetic ketoacidosisThe Turkish Journal of Pediatrics 2017; 59: 318-321

32.BUŞILĂ, C. NECHITA, A., The association between dyslipidemia in children and the risk of cardiovascular disease in young ages.Annals of the University Dunarea de Jos of Galati: Fascicle: XVII, Medicine . 2012, Vol. 17 Issue 2, p43-47. 5p.

33.BUSILA, C., NECHITA, A., COVACI, A., DIRTU, A.C., Expunerea la ftalați și rolul lor în apariția insulinorezistenței și adipogenezei. Jurnalul Pediatrului . 2014 Supplement 1, Vol. 17, p46-47. 2p.

34.SIEW, E.D., FISSELL, W.H., TRIPP, C.M., BLUME, J.D., et col. Acute kidney injury as a Risk Factor for Delirium and Coma during Critical Illness Am J Respir Crit Care Med. 2017 Jun 15;195(12):1597-1607.

35.ASCHENBRENNER, U., NEPPL, S., AHOLLINGER, F., SCHWEIGKOFLER, U., WEIGT, J.O., FRANK, M., ZIMMERMANN, M., BRAUN, J., Einsatz der Luftrettung in der NachtDatenanalyse von Primar- und Sekundäreinsätzen der DRF-Luftrettung des Jahres 2014 Unfallchirurg 2015.118:549-563

36.MINDRU, D.E., MATEI, M.C., RUGINA, A., CIOMAGA, I.M., NISTOR, N., FLORESCU, L., The informed consent in pediatrics - a child's right. Rev Med Chir Soc Med Nat Iasi, 2019, 123(1): 153-160.

37.FLORESCU, L., MATEI, M.C., RUGINA, A., MINDRU, D.E., ANTIGHIN, S.P., MASTALERU, A., TEMNEANU, O.R., Z-score: an indicator of protein-calorie malnutrition. Rev Med Chir Soc Med Nat Iasi, 2017, 121(3): 493-498.

38. AXELSSON, C., BORGSTROM, J., KARLSSON, T.,. AXELSSON, A., HERLITZ, J., Dispatch codes of out-of-hospital cardiac arrest should be diagnosis related rather than symptom related Eur J Emerg Med. 2010 Oct;17(5):265-9.

39.VOINESCU, D.C., CIOBOTARU, O.R., CIOBOTARU, O.C., PREDA, A., LUPU, V.V., COMAN, M.B., ARBUNE, M., Ultrastructural Changes of the Gastric Mucosa Induced by the Helicobacter pylori Infection. Rev Chim., 66, no.12, 2015, p.2104

40.PAVEL, L.L., TIUTIUCA, C., BERBECE, S.I., CONDRATOVICI, A.P., IOANID, N., Chemical Physiology of Muscle Contraction. Rev Chim (Bucharest), 68, no.5, 2017, p.1095-1097.

41.BUSILA, C., STUPARU, M.C., NECHITA, A., GRIGORE, C.A., BALAN, G., Good Glycemic Control for a Low Cardiovascular Risk in Children Suffering from Diabets. Rev Chim., 68, no.2, 2017, p.358

42.BAROIU, L., BEZNEA, A., CONDRATOVICI, C.P., ONISOR, C., GRIGORE, C.A., TOPOR, G., RUGINA, S., Comparative Effectiveness of Vancomycin and Metronidazole for the Initial Episode of Nonsevere Clostridium Difficle Infection. Rev Chim (Bucharest), 70, no.10, 2019, p.3741-3745.

43.BEZNEA, A., TRUS, C.T., CHICOS, S.C., CHEBAC, G.R., CEAUSU, M., Peritoneal malignant mesothelioma. CHIRURGIA 2009; 104(2):227-230.

44.YERSIN, G.C.B., MABIRE, C., PASQUIER, M., ALBRECHT, R., CARRON, P.N., Retrospective analysis of 616 air rescue-trauma cases related to the practice of extreme sports Injury, Int J. Care Injuried $\operatorname{xxx}(2016) \mathrm{xxx}$-xxx

45.ANGHEL, L., BAROIU, L., BEZNEA, A., TOPOR, G., GRIGORE, C.A., The Therapeutic Relevance of Vitamin E. Rev Chim (Bucharest), 70, no.10, 2019, p.3711-3713.

46.MICHAILIDO, M., GOLDSTEIN, S.D., SALAZAR, J., ABOAGYE, J., et col. Haut Helicopter Overtriage in Pediatric Trauma. Journal of Pediatric Surgery 49 (2014) 1673-1677.

$\overline{\text { Manuscript received: 06. 02. } 2020}$ 